\title{
Screening Practices among First Degree Relatives of Breast Cancer Patients in Nepal: A Cross-sectional Study
}

\section{Rashmi Mulmi ${ }^{1}$, Gambhir Shrestha ${ }^{2}$, Surya Raj Niraula ${ }^{3}$, Deepak Kumar Yadav ${ }^{3}$, Paras Kumar Pokharel ${ }^{3}$}

${ }^{1}$ Department of Cancer Prevention, Control and Research, B.P Koirala Memorial Cancer Hospital, Bharatpur, Chitwan, Nepal. ${ }^{2}$ Department of Community Medicine, Maharajgunj Medical Campus, Institute of Medicine, Tribhuvan University, Maharajgunj, Kathmandu, Nepal. ${ }^{3}$ School of Public Health and Community Medicine, B.P Koirala Institute of Health Sciences, Dharan, Sunsari, Nepal.

\begin{abstract}
Objective: Family history is a significant risk factor for development of breast cancer, particularly for women of first-degree relatives. For women at high risk for breast cancer, regular screening is the mainstay of risk management. This study aims to find out the breast cancer screening practices among first degree relatives of breast cancer patient. Methods: A cross-sectional study was carried out among 150 purposively selected first-degree female relatives of breast cancer patients undergoing treatment at B.P Koirala Memorial Cancer Hospital, aged between 20 and 60 years. A semi-structured questionnaire was used to collect data by face to face interview, which included socio-demographic characteristics, personal history, awareness on breast cancer and screening practices. Results: The mean age of the participants was 37.6 years (SD 10.9). A total of 116 (77.3\%) women had ever practiced breast self-examination (regular $=34.7 \%$; irregular $=42.7 \%)$ and $42(28.0 \%)$ had ever practiced clinical breast examination (regular=14.7\%; irregular=13.3\%). Only 10 percent of the women had performed mammogram regularly. Only two-fifth of them had a high level of awareness on risk factors and warning signs of breast cancer. Conclusions: This study showed a low rate of regular screening practices among the first degree relatives of breast cancer patients. There is a need to provide comprehensive, and inclusive information and support and interventions aimed at increasing awareness of the importance of healthy behaviors in cancer prevention among these high-risk groups.
\end{abstract}

Keywords: Breast cancer- Breast self-examination- Clinical breast examination- First degree relatives- Mammogram

Asian Pac J Cancer Care, 6 (3), 297-303
Submission Date: 11/26/2020Ａcceptance Date: 06/10/2021

\section{Introduction}

Breast cancer constitutes a major public health issue in the world. It is the most common cancer in women worldwide with high incidence [1] and the second most common cancer overall with nearly 2.1 million new cases in 2018 representing about $12 \%$ of all new cancer cases and $6.6 \%$ of all cancer deaths [2]. In Asia, there is a significant increase in the incidence of breast cancer among the women in reproductive age group [3] whereas, in the United States and Europe, it peaks among women in their sixties [4]. Also, in South Asia, it is detected more often in younger females and at a more advanced stage as compared to females of other regions [5].
Breast cancer is the second leading cancer among Nepalese women [6]. According to the latest GLOBOCAN data 2018, the age-standardized incidence and mortality rate of breast cancer in Nepal were 15.0 and 15.0 per 100,000 [7]. Family history of breast cancer is one of the significant risk factors for development of the disease, particularly for women with first-degree relatives diagnosed with breast cancer [8]. Risk of breast cancer is about 2-4 times higher for women with first-degree female relative who has been diagnosed compared to women without a family history [9].

The screening practices of women depends on their

Corresponding Author:

Rashmi Mulmi

Department of Cancer Prevention, Control and Research, B.P Koirala Memorial Cancer Hospital, Bharatpur, Chitwan, Nepal.

Email: rashmi.mstha@gmail.com 
awareness, attitudes, socio-demographic characteristics and cultural issues [10]. Breast cancer screening recommendations for women with positive family history are based on expert opinion, and typically dictate shorter screening intervals and screening beginning at an earlier age. Such strategies include annual mammographic screening beginning at age 40 years, or 10 years prior to the earliest age of onset observed in the family (whichever occurs earliest), or starting as young as age 25 years for BRCA mutation carriers [11]. Several studies have found that regular screening in women with a family history is benefitted from reporting higher cancer detection rates and favorable prognostic features of screen-detected cancers $[11,12]$. Knowledge of risk factors for breast cancer and breast screening among women are being studied in Nepal, but none has looked at women with family history of breast cancer. This study is the first in Nepal to find out the breast cancer screening practices among first degree relatives of breast cancer patients and factors associated with it.

\section{Materials and Methods}

\section{Study setting and design}

This was a cross-sectional study carried out among first degree relatives of breast cancer patients attending B.P Koirala Memorial Cancer Hospital (BPKMCH) for their treatment form December 2016 to May 2017. $\mathrm{BPKMCH}$ is situated in Bharatpur, Chitwan district, Central Development Region of Nepal. It is the largest national comprehensive cancer center of its kind. It is a 450 bedded hospital and provides high-quality services for the prevention, diagnosis, treatment and research on cancer, and to gain self-reliance in human resource required for the same.

\section{Inclusion and exclusion criteria}

Sister, daughter, and mother of breast cancer diagnosed women of age group 20 to 60 years accompanying them in the OPD, wards in BPKMCH were included and those with history of previous malignancies were excluded from the study.

\section{Sample size}

In a similar study done in Mexico, $38.7 \%$ of study participants had performed regular mammogram [13]. Based on this proportion, the sample size was calculated using the following formula.

Sample size $(\mathrm{n})=(\mathrm{Z} 1 \text {-á })^{2} \times \mathrm{pq} / \mathrm{1}^{2}$

where, $Z$ (Standard normal variate $)=1.96$ for $95 \%$ Confidence interval.

Prevalence $(p)=0.39$

Compliment of $\mathrm{P}(\mathrm{q})=1-0.39=0.61$

Thus, at $95 \%$ confidence level and $20 \%$ of p allowable error (l), the calculated sample size was 150 .

The estimated sample size in the study was 150 participants.

\section{Methods of data collection}

The sample for the study was selected by nonprobability purposive sampling method. The data were collected by the corresponding author via face-toface interviews using semi-structured questionnaires examining following parts:

Part I comprised of socio-demographic characteristics, information regarding the relative (women with breast cancer) and personal medical history of the participant. The employment of the participants was classified according to Nepal Standard Classification of Occupation (NSCO-99). Economic status was measured based on the measure of poverty line as defined by the World Bank. It is the minimum level of income deemed adequate in a particular country. In October 2015, the World Bank updated the international poverty line to $\$ 1.90$ a day. The economic status of the participants was classified as "below Poverty line" if per capita income $\leq$ USD 1.90 and "above Poverty line" if per capita income $>$ USD 1.90 (1 USD = NRs 107). The level of education was classified according to Ministry of Education 2010 as illiterate, primary if Grade 1-5, Secondary if Grade 6-10 and higher secondary and above if Grade 11 and above [14].

Part II comprised of level of awareness of the participant on risk factors and warning signs of breast cancer as adopted from comprehensive breast cancer knowledge test (CBCKT) with some modifications [15]. This tool consists of 20 statements: 12 statements related to risk factors and 8 statements related to warning signs of breast cancer. Response to each statement included 'Yes', 'No' and 'Don't know'. For a correct response to any statements, a score of 1 was provided while an incorrect response or a response indicating 'Don't know' was scored 0 . A composite score of all the items combined was calculated and the level of awareness was grouped into two categories: "high level" and "low level" after dichotomization taking the median as the cut-off point.

Part III comprised of the perceived risk of developing breast cancer of the participant in their lifetime. The perceived risk was expressed in a numerical rating scale which ranges from $0 \%$ to $100 \%$, where $0 \%$ means no risk at all and $100 \%$ means will absolutely develop cancer in future.

Part IV comprised of semi-structured questionnaires to assess the screening practices of the participants: Breast self-examination, Clinical breast examination and Mammogram practice were included in this part. Screening practices were characterized into two variables: regular screening practices done and not done. Regular screening practices of the participants were defined as performance of any of the screening modalities: monthly breast self-examination, yearly or 2 yearly clinical breast examination and yearly or 2 yearly mammogram. The irregular performers and those who had never performed were categorized into not practiced group. Mammography and Clinical breast examination screening practice of the participants were characterized by reason and time since the last examination. Breast selfexamination practice was assessed by the self-reported frequency of performance of breast cancer. 
Content validity of the questionnaire was established by a literature review and consultation with concerned faculties and experts. All sets of questionnaire were translated into Nepali version and re-translated into English language by independent two experts. Opinion from the language expert was obtained for comprehensibility and simplicity of language during language translation. Pretesting of the tool was done in $10 \%$ of the total sample size i.e. 15 samples in Bhaktapur Cancer Hospital, Bhaktapur, Nepal. Necessary modifications, such as sequence of the questions, modification in options, simplicity of the language were done.

\section{Statistical analysis}

The collected data was entered, and coded in Microsoft Excel 2007 and exported into Statistical Package for Social Sciences (SPSS) version 17 for statistical analysis. Descriptive statistics (frequency, percentage, mean and standard deviation, median and inter-quartile range) were calculated along with tabular and graphical presentation.

The study was approved by the Institutional Review Committee (IRC), B.P. Koirala Institute of Health Sciences (BPKIHS). Permission to conduct the study in BPKMCH was taken from the academic department of the hospital. All the procedures were carried out after obtaining informed consent from the participants. The participants were assured about the confidentiality and anonymity of their information provided. They were informed that they have full authority to accept or refuse to take part in the study; and were also at liberty to withdraw at any time of the study.

\section{Results}

Socio-demographic characteristics

A total of 150 respondents were included in this study with the mean age of 37.6 years (SD-10.9). Most of them were Hindus (68.7\%) followed by Buddhist (21.3\%). A majority $(75 \%)$ of the respondents were married. Most of the respondents belonged to nuclear family $(62.0 \%)$ and the rest belonged to joint families. Most of the respondents were homemaker $(24.7 \%)$, followed by professional (16.0\%) and agriculture (14.7\%). Only $14 \%$ were unemployed. Most of the respondents (68.0\%) were literate. The respondents below poverty line and above poverty line were in the ratio of $2: 3$. Majority of the respondents were non-insured $(80.7 \%)$. Almost half of the respondents had their mother diagnosed with breast cancer. The respondents who had their sisters diagnosed with breast cancer were $40 \%$. Only $11.3 \%$ of the respondents had their daughter suffering from breast cancer. The duration of breast cancer was less than one year in most of the relatives of respondents $(66.0 \%)$ whereas $34 \%$ of the relatives of respondents had duration of breast cancer one year and more. Majority of respondents $(93.3 \%)$ had only one relative with breast cancer while the rest had two relatives with breast cancer (Table 1).

\section{Personal history}

Approximately $42.7 \%$ of the women had menarche at the age of 11 years and below. The mean age at menarche was 11.6 (SD 1.5) years. Out of 150 respondents, 112 respondents had given birth to their first child, among whom $57.1 \%$ had given birth of the first child below the age of 20 years. More than half of the respondents had good self-reported health status whereas $28 \%$ rated their health as very good. Only 4 percent of the women stated poor health status. Only 14.7 percent of the women had history of benign breast diseases (BBD). The most common benign breast disease among those women was breast lump (40.9\%) which was followed by mastalgia $(31.8 \%)$. The least common benign breast disease was mastitis $(9.0 \%)$ (Table 1$)$.

\section{Level of awareness of the respondents}

The mean score of the respondents on CBCKT score was found to be 10.8 (SD 2.8). Likewise, the median score was 11 (IQR 9-13). The level of awareness of respondents was categorized into low level and high level taking median score 11 as cut off value. The ratio of the respondents with low level of awareness to high level of awareness was found to be $2: 3$. About $54.6 \%$ of the respondents perceived their risk of developing breast cancer in their lifetime as 50\% and above (Table 2).

\section{Practice of breast screening methods}

Majority of the respondents had heard about the breast cancer screening methods. Self-breast examination (88\%) was the most common screening method familiar within the respondents. Mammography was the least heard screening method. A total of $116(77.3 \%)$ women had ever practiced breast self-examination (regular $=34.7 \%$, irregular $=42.7 \%$ ) and $42(28.0 \%)$ had ever practiced clinical breast examination (regular $=14.7 \%$, irregular $=13.3 \%$ ). Only 10 percent of the women had performed mammogram regularly as recommended. Majority of the respondents had never practiced mammogram. The practice of mammogram was further analyzed among the respondent aged 40 above years, as it is recommended after the age 40 years. Thus, the overall practice of mammogram among the eligible age group was found to be $18(27.3 \%)$ (Table 3).

\section{Discussion}

The first degree relatives of breast cancer are in greater risk of developing breast cancer. This is the first study in Nepal, to the best of our knowledge, to investigate the screening practices among the first degree relatives of breast cancer. Early menarche is one of the risk factors of breast cancer, thus finding of the study shows that 42.7 percent of the women are exposed to one of the risk factors of breast cancer [16]. Only 14.7 percent of the respondents had history of benign breast disease, which was similar to the finding in another study done in Philippines [17]. Women with a family history of breast cancer are more likely to develop benign breast disease and are also at increased risk for developing high-risk 
Table 1. Socio-demographic Characteristics and Personal Medical History of the Respondents ( $\mathrm{n}=150)$

\begin{tabular}{|c|c|c|c|}
\hline Socio-demographic Characteristics & Categories & Frequency (n) & Percentage $(\%)$ \\
\hline \multirow[t]{4}{*}{ Age in years } & $20-29$ & 42 & 28 \\
\hline & $30-39$ & 42 & 28 \\
\hline & $40-49$ & 37 & 24.7 \\
\hline & $\geq 50$ & 29 & 19.3 \\
\hline \multicolumn{4}{|l|}{ Mean age in years \pm SD (Min-Max) $37.6 \pm 10.9(20-60)$} \\
\hline \multirow[t]{4}{*}{ Religion } & Hindu & 103 & 68.7 \\
\hline & Buddhist & 32 & 21.3 \\
\hline & Muslim & 9 & 6 \\
\hline & Christian & 6 & 4 \\
\hline \multirow[t]{4}{*}{ Marital status } & Unmarried & 32 & 21.3 \\
\hline & Married & 109 & 72.7 \\
\hline & Divorced/Separated & 4 & 2.7 \\
\hline & Widow & 5 & 3.3 \\
\hline \multirow[t]{2}{*}{ Family type } & Nuclear & 93 & 62 \\
\hline & Joint & 57 & 38 \\
\hline \multirow[t]{7}{*}{ Occupation } & Unemployed & 21 & 14 \\
\hline & Agriculture & 22 & 14.7 \\
\hline & Laborer & 12 & 8 \\
\hline & Professional & 24 & 16 \\
\hline & Business & 16 & 10.7 \\
\hline & Student & 18 & 12 \\
\hline & Homemaker & 37 & 24.7 \\
\hline \multirow[t]{4}{*}{ Education } & Illiterate & 48 & 32 \\
\hline & Primary & 8 & 5.3 \\
\hline & Secondary & 47 & 31.3 \\
\hline & Higher secondary and above & 47 & 31.3 \\
\hline \multirow[t]{2}{*}{ Economic status } & Below poverty line & 60 & 40 \\
\hline & Above poverty line & 90 & 60 \\
\hline \multirow[t]{2}{*}{ Distance between nearest health facility from home } & $\leq 30 \mathrm{~min}$ & 113 & 75.3 \\
\hline & $>30 \mathrm{~min}$ & 37 & 24.7 \\
\hline \multirow[t]{2}{*}{ Medical insurance status } & Insured & 29 & 19.3 \\
\hline & Non-insured & 121 & 80.7 \\
\hline \multirow[t]{3}{*}{ Relationship with the patient } & Daughter & 17 & 11.3 \\
\hline & Mother & 72 & 48 \\
\hline & Sister & 61 & 40.7 \\
\hline \multirow[t]{2}{*}{ Duration of disease ( in years) } & $<1$ & 99 & 66 \\
\hline & $\geq 1$ & 51 & 34 \\
\hline \multirow[t]{2}{*}{ Number of relatives with breast cancer } & One & 140 & 93.3 \\
\hline & Two & 10 & 6.7 \\
\hline \multirow[t]{2}{*}{ Age at menarche (in years) } & $\leq 11$ & 64 & 42.7 \\
\hline & $>11$ & 86 & 57.3 \\
\hline \multicolumn{4}{|c|}{ Mean age at menarche in years \pm SD (Min-Max) $11.6 \pm 1.5(8-16)$} \\
\hline \multirow[t]{2}{*}{ Age at first birth $(\mathrm{n}=112)$ (in years) } & $\leq 20$ & 64 & 57.1 \\
\hline & $>20$ & 48 & 42.9 \\
\hline \multirow[t]{4}{*}{ Self-reported health status } & Poor & 6 & 4 \\
\hline & Good & 83 & 55.3 \\
\hline & Very good & 43 & 28.7 \\
\hline & Excellent & 18 & 12 \\
\hline \multirow[t]{2}{*}{ Presence of benign breast disease (BBD) } & Yes & 22 & 14.7 \\
\hline & No & 128 & 85.3 \\
\hline
\end{tabular}


Table 2. Level of Awareness on Risk Factors and Warning Signs of Breast Cancer and Perceived Risk of Developing Breast Cancer of Respondents $(n=150)$

\begin{tabular}{lcc}
\hline Variables & Frequency $(\mathrm{n})$ & Percentage $(\%)$ \\
\hline Level of awareness & & \\
Low level & 60 & 40 \\
High level & 90 & 60 \\
Perceived risk & & \\
Less than 50\% & 68 & 45.4 \\
$50 \%$ and more & 82 & 54.6 \\
\hline
\end{tabular}

types of BBD such as atypical hyperplasia [11].

More than half of the respondents were aware of the risk factors like early menarche, delayed menopause, positive family history and also the protective role of breastfeeding and exercise. In another study done in Nepal, awareness on these risk factors was found to be low in contrast to the above findings of the present study [18]. The reason behind this contrasting result could be, in the present study only first-degree female relatives of breast cancer patients were considered whereas, in another study, the participants were general population. As our study group is a risk group they might have enquired about the disease and may have gained knowledge.

In the present study, majority of the respondents were aware of screening procedures. The self-breast examination was the most known screening procedure among the respondents and mammogram was the least known. This finding correlates with the result of the study done in Malaysia [19]. On the other hand, in a study done in Nepal among the female residents of Pokhara valley, more than half of the respondents were unaware of clinical breast examination and mammogram [5]. This suggests that compared to general population, these high-risk group women are more aware of the screening procedures. Nevertheless, every woman should have access to information on screening modalities.

The present study reveals that majority $(77.3 \%)$ of the respondents had ever performed breast self-examination. Likewise, in Nigeria, 61.4 percent of the first degree relatives of breast cancer had ever performed breast self-examination [20]. The women who had practiced monthly breast self-examination account for 34.7 percent of women among total respondents. On the other hand, in various studies done among the women without positive family history of breast cancer, the proportion of women performing breast self-examination in regular basis was found to be lower than the finding of the present study i.e. 15 percent in India, 10.2 percent in Iran and 17 percent in Nepal respectively [10, 21, 22].
As in the present study, the proportion of women conducting breast self-examination was high; however the regular performers were rather low. Similarly, in another study, 92.6 percent of the women had ever performed BSE but, only 30.1 percent of the women were the regular performers [23]. In the present study, majority of the respondents had not performed clinical breast examination and only 4.8 percent had done annually. This finding was in accordance with those reported in a study by Tilaki et.al. in Iran where 74.5 percent of the women had never visited for clinical breast examination and only 8.4 percent of the women performed annually [10]. In contrast to above findings, previous studies done among women with positive family history reported, 84 percent of the respondents had reported of performing clinical breast examination $[13,24]$.

Only 12.7 percent of the women had ever performed mammogram at least once in their lifetime. This finding was likely similar to the finding of another study done in Malaysia in which 19.1 percent of women had practiced mammogram [19]. Likewise, the practice of doing mammogram was found to be similar in another study done in Nepal among women with no positive family history of breast cancer [25]. A higher rate of screening mammography above age 40 years was reported in similar study done in USA [26]. This shows the vast difference in screening practice of Nepalese women and American women. This might be because of difference in female literacy rate of the two countries and the facility of mammogram in the health center. In Nepal, mammogram facility is not easily available in all health centers.

Perceived risk of breast cancer was found to be predictor for breast cancer screening practices similar to other studies [27]. A meta-analysis reported that perceived risk among women with a family history of breast cancer higher than other women and found positive association between higher perceived risk and mammography screening [28].

Regular screening practices are influenced by the level of awareness on risk factors and warning signs of breast cancer in other studies $[10,29]$. However, in a study done by Karma; level of awareness and screening practices were found to be independent of each other [30]. Thus, this shows that there is need for proper counseling to the women for screening despite their high level of awareness.

In the current study, regular screening practices of the respondents are influenced by their familiarity with hereditary breast cancer. The screening uptake was higher among the women who were counseled about hereditary breast cancer [31].

Various modifiable and non-modifiable risk factors of

Table 3. Breast Screening Practices among the Respondents $(n=150)$

\begin{tabular}{lcccc}
\hline Breast screening Practices & Heard $\mathrm{n}(\%)$ & Practice $\mathrm{n}(\%)$ \\
& & $52(34.7)$ & $64(42.7)$ & $34(22.6)$ \\
\hline Self-examination & $132(88.0)$ & $22(14.7)$ & $20(13.3)$ & $108(72)$ \\
Clinical examination & $109(72.7)$ & $15(10.0)$ & $4(2.7)$ & $131(87.3)$ \\
Mammogram & $105(70.0)$ & Irregular & \\
\hline
\end{tabular}


breast cancer have been studied so far. Family history is one important non-modifiable risk factor. Therefore, adherence to screening methods is crucial for early detection and better prognosis. Paradoxically, a large proportion of women with a family history of breast cancer do not make use of available screening methods. Moreover, irregular screening practices and poor competency in performing self-breast examination could miss the chance of early detection of cancer leading to late-stage presentation. This puts a high burden on the already overburdened healthcare services. Awareness of different screening modalities should be raised among these women. Future studies should try to explore the lived experiences of women with positive family history of breast cancer, using qualitative approach. This will help to understand better how the family experience influences their practice of breast screening.

There are some limitations to the study. First, the data was collected from one hospital and non-probability sampling was used, thus this study cannot be generalized. However, the chosen hospital is the largest and nationally representative cancer hospital where $50 \%$ of the cancer cases from around Nepal are treated. Furthermore, this study does not allow us to make definitive inferences about the effect of risk factors associated with screening practices, as it has a cross-sectional design and this study used self-reported data.

In conclusion, screening practices among the first degree relatives of breast cancer patients were found to be low in the present study. Likewise, the level of awareness on risk factors and warning signs of breast cancer was also found to be low among the respondents. There is a need to provide comprehensive, updated, and inclusive information and support and interventions aimed at increasing awareness of the importance of healthy behaviors in cancer prevention among these high-risk groups.

\section{Acknowledgements}

We express our gratitude to the B.P. Koirala Memorial Cancer Hospital for giving us permission to conduct this study. We are thankful to all the participants who helped us and participated in the study.

\section{Funding Statement}

None

\section{Conflict of Interests}

The authors declare that they have no competing interests.

\section{References}

1. Fitzmaurice C, Dicker D, Pain A, Hamavid H, Moradi-Lakeh M, MacIntyre MF, Allen C, et al. The Global Burden of Cancer 2013. JAMA Oncology. 201507 01;1(4):505. https:// doi.org/10.1001/jamaoncol.2015.0735

2. Bray F, Ferlay J, Soerjomataram I, Siegel RL, Torre LA, Jemal A. Global cancer statistics 2018: GLOBOCAN estimates of incidence and mortality worldwide for 36 cancers in 185 countries. CA: A Cancer Journal for Clinicians. 2018 09 12;68(6):394-424. https://doi.org/10.3322/caac.21492

3. Simonsen K. Breast cancer knowledge and attitudes among women in armenia. The University of Utah; 2013.

4. Khokhar A. Breast Cancer in India: Where Do We Stand and Where Do We Go?. Asian Pacific Journal of Cancer Prevention. 2012 Oct 31;13(10):4861-4866. https://doi. org/10.7314/apjcp.2012.13.10.4861

5. Bhatt V, Wetz R, Shrestha R, Shrestha B, Shah N, Sayami P, Gurung C, Weiserbs K. Breast cancer knowledge, attitudes and practices among Nepalese women. European Journal of Cancer Care. 201108 10;20(6):810-817. https://doi. org/10.1111/j.1365-2354.2011.01272.x

6. Sharma A, Zhang J. Depression and its predictors among breast cancer patients in Nepal. ASEAN Journal of Psychiatry. 2014;16(1):106-15.

7. GLOBOCAN. The global cancer observatory: Nepal factsheet [Online]. Lyon, France: International Agency for Research on Cancer, World Health Organization, 2018 . Available: http://gco.iarc.fr/today/data/factsheets/populations/524nepal-fact-sheets.pdf [Accessed Feb 18 2019].

8. Ormseth S. Screening adherence and emotional adjustment of daughters of breast cancer patients. Screening. 2013;9:12013.

9. Familial breast cancer: collaborative reanalysis of individual data from 52 epidemiological studies including 58209 women with breast cancer and 101986 women without the disease. The Lancet. 2001 Oct;358(9291):1389-1399. https:// doi.org/10.1016/s0140-6736(01)06524-2

10. Hajian Tilaki K, Auladi S. Awareness, Attitude and Practice of Breast Cancer Screening Women, and the Associated Socio-Demographic Characteristics, in Northern Iran. Iranian Journal of Cancer Prevention. 201508 24;8(4). https://doi.org/10.17795/ijcp.3429

11. Walker M. Breast cancer screening behaviours and outcomes in women with a family history of breast and/or ovarian cancer in Ontario . University of Toronto; 2014.

12. Kartal M, Ozcakar N, Hatipoglu S, Tan MN, Guldal AD. Breast cancer risk perceptions of Turkish women attending primary care: a cross-sectional study. BMC Women's Health. 2014 Dec;14(1). https://doi.org/10.1186/s12905-014-0152-3

13. Yelena Bird, John Moraros, Matthew P. Banegas, Sasha King, Surasri Prapasiri, Beti Thompson. Breast Cancer Knowledge and Early Detection among Hispanic Women with a Family History of Breast Cancer along the U.S.-Mexico Border. Journal of Health Care for the Poor and Underserved. 2010;21(2):475-488. https://doi.org/10.1353/hpu.0.0292

14. Ravallion M, Chen S, Sangraula P. Dollar a day revisited. World Bank Econ Rev. 2009;23(2):163-84. https://doi. org/10.1093/wber/lhp007

15. Stager JL. The comprehensive Breast Cancer Knowledge Test: validity and reliability. J Adv Nurs. 1993 Jul;18(7):1133-40. https://doi: 10.1046/j.1365-2648.1993.18071133.x. PMID: 8370905.

16. Breast cancer facts \& figures 2015-2016. Available at: www.cancer.org/acs/groups/content/.../acspc-046381.pdf. [Accessed August 09 2018]. 
17. Kashiwagi Y, Kakinohana S. Breast Cancer Knowledge and Preventive Behavior Among Filipino Women in a Rural Area: A Cross-Sectional Study. Nursing and Midwifery Studies. 201606 01;5(3). https://doi.org/10.17795/nmsjournal34300

18. Bhandari PM, Thapa K, Dhakal S, Bhochhibhoya S, Deuja R, Acharya P, Mishra SR. Breast cancer literacy among higher secondary students: results from a cross-sectional study in Western Nepal. BMC Cancer. 201602 18;16(1). https://doi. org/10.1186/s12885-016-2166-8

19. Subramanian P, Oranye NO, Masri AM, Taib NA, Ahmad N. Breast Cancer Knowledge and Screening Behaviour among Women with a Positive Family History: A Cross Sectional Study. Asian Pacific Journal of Cancer Prevention. 2013 Nov 30;14(11):6783-6790. https://doi.org/10.7314/ apjcp.2013.14.11.6783

20. Adelekan AL. Awareness, Knowledge and Practices of Breast Cancer Prevention among Women with Family History of Breast Cancer in Ede, Osun State, Nigeria. IOSR Journal of Dental and Medical Sciences. 2012;2(2):42-47. https://doi. org/10.9790/0853-0224247

21. Ahuja S, Chakrabarti N. To determine the level of knowledge regarding breast cancer and to increase awareness about breast cancer screening practices among a group of women in a tertiary care hospital in Mumbai, India. Int J Public Health. 2010;1(1).

22. Shrestha K. Breast cancer knowledge and screening practice among women visited to KIST medical college. Nepal Med Coll J. 2012;14(4):308-11.

23. Erdem Ö, Toktaş İ. Knowledge, Attitudes, and Behaviors about Breast Self-Examination and Mammography among Female Primary Healthcare Workers in Diyarbakır, Turkey. BioMed Research International. 2016;2016:1-6. https://doi. org/10.1155/2016/6490156

24. Tunin R, Uziely B, Woloski-Wruble AC. First degree relatives of women with breast cancer: who's providing information and support and who'd they prefer. Psycho-Oncology. 2010 04;19(4):423-430. https://doi.org/10.1002/pon.1596

25. Sathian B, Nagaraja SB, Banerjee I, Sreedharan J, De A, Roy B, Rajesh E, Senthilkumaran S, Hussain SA, Menezes RG. Awareness of Breast Cancer Warning Signs and Screening Methods among Female Residents of Pokhara Valley, Nepal. Asian Pacific Journal of Cancer Prevention. 201406 15;15(11):4723-4726. https://doi.org/10.7314/ apjcp.2014.15.11.4723

26. Hibler L. Screening mammography among women with a family history of breast cancer. 2014.

27. Zhang LR, Chiarelli AM, Glendon G, Mirea L, Edwards S, Knight JA, Andrulis IL, Ritvo P. Influence of perceived breast cancer risk on screening behaviors of female relatives from the Ontario site of the Breast Cancer Family Registry. European Journal of Cancer Prevention. 2011 07;20(4):255262. https://doi.org/10.1097/cej.0b013e3283447467

28. Katapodi MC, Lee KA, Facione NC, Dodd MJ. Predictors of perceived breast cancer risk and the relation between perceived risk and breast cancer screening: a meta-analytic review. Preventive Medicine. 2004 04;38(4):388-402. https://doi.org/10.1016/j.ypmed.2003.11.012

29. Komenaka IK, Nodora JN, Hsu C, Martinez ME, Gandhi SG, Bouton ME, Klemens AE, Wikholm LI, Weiss BD. Association of Health Literacy With Adherence to Screening Mammography Guidelines. Obstetrics \& Gynecology. 2015 04;125(4):852-859. https://doi. org/10.1097/aog.0000000000000708

30. Rabon-Stith $\mathrm{K}$. The relationship between select variables and the breast cancer screening practices of a convenient sample of African-American women from Grambling State University and the Willis-Knighton Neighborhood Clinic.
Virginia Tech. 2001.

31. Elobaid YE, Aw TC, Grivna M, Nagelkerke N. Breast Cancer Screening Awareness, Knowledge, and Practice among Arab Women in the United Arab Emirates: A Cross-Sectional Survey. Al-Wadei HA. PLoS ONE. 201409 29;9(9):e105783. https://doi.org/10.1371/journal.pone.0105783

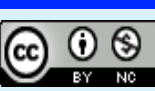

This work is licensed under a Creative Commons AttributionNon Commercial 4.0 International License. 